\title{
Flutamide Induces Hepatic Cell Death and Mitochondrial Dysfunction via Inhibition of Nrf2-Mediated Heme Oxygenase-1
}

\author{
Li Zhang, ${ }^{1,2}$ Jiabin Guo $\mathbb{D}^{2}{ }^{2}$ Qiang Zhang $\left(\mathbb{D},{ }^{3}\right.$ Wei Zhou, ${ }^{1}$ Jin Li, ${ }^{4}$ Jian Yin, ${ }^{2}$ Lan Cui, ${ }^{2}$ \\ Tingfen Zhang, ${ }^{2}$ Jun Zhao, ${ }^{2}$ Paul L. Carmichael, ${ }^{4}$ Alistair Middleton, ${ }^{4}$ \\ and Shuangqing Peng $\mathbb{C}^{2}$ \\ ${ }^{1}$ Academy of Military Medical Sciences, Beijing 100850, China \\ ${ }^{2}$ Evaluation and Research Centre for Toxicology, Institute of Disease Control and Prevention, PLA, Beijing 100071, China \\ ${ }^{3}$ Department of Environmental Health, Rollins School of Public Health, Emory University, Atlanta, GA 30322, USA \\ ${ }^{4}$ Unilever Safety and Environmental Assurance Center, Colworth Science Park, Sharnbrook, Bedfordshire MK44 1LQ, UK
}

Correspondence should be addressed to Jiabin Guo; gjb321@163.com and Shuangqing Peng; pengsq@hotmail.com

Received 23 February 2018; Revised 22 April 2018; Accepted 10 May 2018; Published 2 July 2018

Academic Editor: Shao-Yu Chen

Copyright @ $2018 \mathrm{Li}$ Zhang et al. This is an open access article distributed under the Creative Commons Attribution License, which permits unrestricted use, distribution, and reproduction in any medium, provided the original work is properly cited.

\begin{abstract}
Flutamide is a widely used nonsteroidal antiandrogen for prostate cancer therapy, but its clinical application is restricted by the concurrent liver injury. Increasing evidence suggests that flutamide-induced liver injury is associated with oxidative stress, though the precise mechanism is poorly understood. Nuclear factor erythroid 2-related factor 2 (Nrf2) is a master transcription factor regulating endogenous antioxidants including heme oxygenase-1 (HO-1). This study was designed to delineate the role of Nrf2/HO-1 in flutamide-induced hepatic cell injury. Our results showed that flutamide concentration dependently induced cytotoxicity, hydrogen peroxide accumulation, and mitochondrial dysfunction as indicated by mitochondrial membrane potential loss and ATP depletion. The protein expression of Nrf2 and HO-1 was induced by flutamide at $12.5 \mu \mathrm{M}$ but was downregulated by higher concentrations of flutamide. Silencing either Nrf2 or HO-1 was found to aggravate flutamide-induced hydrogen peroxide accumulation and mitochondrial dysfunction as well as inhibition of the Nrf2 pathway. Moreover, preinduction of HO-1 by Copp significantly attenuated flutamide-induced oxidative stress and mitochondrial dysfunction, while inhibition of HO-1 by Snpp aggravated these deleterious effects. These findings suggest that flutamide-induced hepatic cell death and mitochondrial dysfunction is assoicated with inhibition of Nrf2-mediated HO-1. Pharmacologic intervention of Nrf2/HO-1 may provide a promising therapeutic approach in flutamide-induced liver injury.
\end{abstract}

\section{Introduction}

Flutamide (Flu, 2-methyl-N-[4-nitro-3-(trifluoromethyl) phenyl] propanamide) is an oral, widely used nonsteroidal antiandrogen approved for the treatment of prostate cancer [1]. Although generally considered safe, flutamide therapy is compromised by the occurrence of hepatotoxicity [2]. Flutamide can induce cholestasis, jaundice, and liver necrosis, which may eventually require a liver transplant. Because of the concurrent hepatotoxicity, flutamide received a black box warning label by the FDA in 1999 [3]. Mitochondrial injury is increasingly proposed as a putative hazard of flutamide though the susceptibility factors which are unknown
[4]. Experimental evidence has shown that flutamide can inhibit mitochondrial complex I [5], induce ATP depletion [6], and disrupt mitochondrial membrane potential (MMP) [7] in cultured hepatic cells. Studies using different mouse models have revealed that flutamide impaired glucose homeostasis and triggered mitochondrial dysfunction [8]. These findings suggest that mitochondria play a critical role in flutamide-induced liver injury. However, the mechanisms of flutamide-induced mitochondrial damage and liver injury remain elusive.

Mitochondria are the main sites of oxidative phosphorylation and energy metabolism. Meanwhile, mitochondria are also major intracellular sources of reactive oxygen species 
(ROS). Mitochondrial ROS can physiologically act as important redox signaling molecules and play an important role in maintaining cellular oxidant/antioxidant balance. However, excessive ROS production can cause mitochondrial damage that may eventually lead to liver diseases [9]. Emerging evidence implicates that flutamide-induced hepatotoxicity is associated with ROS-mediated oxidative stress [10]. During the metabolism of flutamide in the liver, it is oxidatively metabolized by microsomal metabolic enzymes and turned into electrophilic metabolites. Meanwhile, ROS are also produced as by-products. It has been shown that flutamide induces ROS formation and other prooxidant radicals leading to oxidative stress and mitochondrial dysfunction in primary cultured hepatocytes [4].

Nuclear factor-erythroid 2-related factor 2 (Nrf2) is a master transcription factor regulating the oxidative stress response [11]. Nrf2 is particularly important during times of severe oxidative stress through its ability to regulate the expression of antioxidant proteins and phase II enzymes, such as heme oxygenase-1 (HO-1), NAD(P)H: quinone oxidoreductase 1 (NQO1), and glutathione-S-transferases (GST). Recent studies have shown that HO-1 plays a key role in counteracting oxidative stress and mitochondrial damage $[12,13]$. HO- 1 is a highly inducible antioxidant enzyme that can be induced under a number of conditions, such as oxidative stress, infection, inflammation, and hypoxia [14]. HO-1 converts potentially toxic heme released by mitochondria into the antioxidant biliverdin. Degradation of heme results in the release of iron and production of $\mathrm{CO}$, which functions as a key signal that independently upregulates cellular ironresponsive and antioxidant defense [14]. In addition, CO can bind to the reduced $\mathrm{A} 3$ heme of cytochrome $\mathrm{C}$ oxidase (COX), which enhances mitochondrial hydrogen peroxide release and contributes to retrograde activation of mitochondrial biogenesis.

Increasing evidence suggests that the Nrf2 pathway is critically involved in drug-induced liver injury [15]. It is implicated that many drug-induced hepatotoxicity is attributed to the inhibition of the Nrf2 pathway while its activation was found to provide effective protection against liver injury [16-18]. However, the precise role of HO-1 in flutamideinduced hepatotoxicity is poorly understood. According to the TT21C report entitled "Toxicity Testing in the Twenty First Century: Vision and Strategy" released by the USA National Research Council (NRC, 2007), toxicity pathwaybased drug safety assessments have been proposed as a central part in toxicity testing in the 21 st century. As depicted by that report which was regarded as a milestone in toxicology, toxicity testing strategy is undergoing a tremendous transformation from traditional animal tests to in vitro approaches and other nonanimal alternatives that primarily and preferably use human-originated cells/cell lines. In compliance with this report, we utilized HepG2 cells to explore the role of the Nrf2/HO-1 pathway in flutamide-induced toxicity. We demonstrated that flutamide-induced hepatic cell death, oxidative stress, and mitochondrial dysfunction are through the inhibition of Nrf2-mediated HO-1 induction. Preinduction of HO-1 protected against flutamide-induced hepatic mitochondrial dysfunction. In contrast, inhibition of HO-1 exacerbated flutamide-induced hepatotoxicity. These findings highlight an important role of HO-1 in flutamide-induced liver injury and suggest that $\mathrm{Nrf} 2 / \mathrm{HO}-1$ may be a promising therapeutic target for preventing and treating drug-induced liver injury.

\section{Materials and Methods}

2.1. Cell Culture and Drug Treatments. HepG2 cells were obtained from Shanghai Cell Line Bank (Shanghai, China) and routinely cultured in MEM supplemented with $10 \%$ FBS, $100 \mathrm{U} / \mathrm{mL}$ penicillin, and $100 \mu \mathrm{g} / \mathrm{mL}$ streptomycin. Cell cultures were grown at $37^{\circ} \mathrm{C}$ in humidified incubators containing an atmosphere of $5 \% \mathrm{CO}_{2}$. All cells used in our experiments were up to passage 20. Cells were treated with flutamide (Sigma-Aldrich, USA) for $24 \mathrm{~h}$ at various concentrations as indicated. In some experiments, cells were pretreated with or without $20 \mu \mathrm{M}$ tin protoporphyrin (Snpp, Sigma-Aldrich) or $10 \mu \mathrm{M}$ cobalt protoporphyrin (Copp, Sigma-Aldrich) for $1 \mathrm{~h}$ followed by treatment with $50 \mu \mathrm{M}$ flutamide.

2.2. Evaluation of Cytotoxicity. Cytotoxicity was evaluated by the determination of cell viability and lactate dehydrogenase (LDH) leakage. Cell viability was assessed by using a commercial cell counting Kit-8 (CCK8, Dojindo Molecular Technologies, Japan) according to the manufacturer's instruction. Briefly, immediately after drug treatment, cells were incubated with CCK-8 working solution at $37^{\circ} \mathrm{C}$ for $2 \mathrm{~h}$. Subsequently, the absorbance at $450 \mathrm{~nm}$ was monitored using a microplate reader (Multiskan MK3, Thermo Fisher Scientific, USA). Data were normalized to the values from control cultures without drug treatment which were considered $100 \%$ survival.

$\mathrm{LDH}$ release into the medium was measured to estimate the extent of cell damage. At the end of drug treatment, supernatants of culture media were collected for LDH assay. The activity of $\mathrm{LDH}$ was measured by recording the absorbance at $490 \mathrm{~nm}$ using a cytotoxicity LDH assay kit (Beyotime Biotechnology, China).

2.3. Determination of Hydrogen Peroxide Content. Hydrogen peroxide was measured using a hydrogen peroxide assay kit based on ferrous oxidation of xylenol orange assay according to the manufacturer's instructions (Beyotime Institute of Biotechnology, China). Cells were freshly collected and lysed immediately after drug treatments. Cell lysate was centrifuged at $12,000 \mathrm{~g}$ at $4^{\circ} \mathrm{C}$ for $5 \mathrm{~min}$. The supernatant was collected and incubated with a hydrogen peroxide detecting reagent at room temperature for $30 \mathrm{~min}$. Absorbance at $560 \mathrm{~nm}$ was then monitored by a microplate reader.

2.4. Detection of Mitochondrial Membrane Potential. Mitochondrial membrane potential was indicated by a MitoTracker ${ }^{\circledR}$ probe (Invitrogen) which contains a mildly thiolreactive chloromethyl moiety for labeling mitochondria. After completion of drug treatment, cells were incubated with staining solution containing $100 \mathrm{nM}$ MitoTracker probe in the dark at $37^{\circ} \mathrm{C}$ for $30 \mathrm{~min}$. Thereafter, cells were washed at least thrice with prewarmed PBS to completely remove 


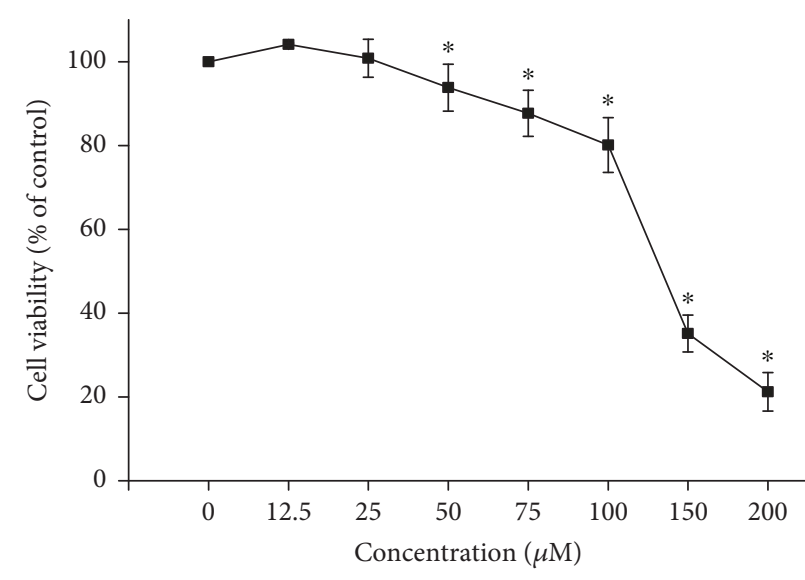

(a)



(b)

FIGURE 1: Flutamide concentration dependently induced cytotoxicity in HepG2 cells. Cells were treated with flutamide at various concentrations $(0-200 \mu \mathrm{M})$ for $24 \mathrm{~h}$. Cytotoxicity was evaluated by CCK-8 assays for cell viability (a) and LDH assays for LDH leakage (b). Data are presented as the mean \pm SD from 3 independent experiments. ${ }^{*} P<0.05$ compared with the cells in the control group without drug treatment.

extra probe. The fluorescence intensity of MitoTracker probe was measured using a FACS Calibur flow cytometer (Becton Dickinson, USA).

2.5. Determination of ATP. Cellular ATP content was determined by ATP colorimetric assay (BioVision) by utilizing the phosphorylation of glycerol to generate a product that is quantified by colorimetric methods. Samples were collected and processed according to the manufacturer's instruction. In brief, cells were lysed in an ATP assay buffer, followed by deproteinizing using a deproteinization sample preparation kit (BioVision). The samples were then mixed with ATP assay buffer, along with reaction mix and an ATP probe. The reaction system was incubated in the dark at room temperature for $30 \mathrm{~min}$. Thereafter, absorbance at $570 \mathrm{~nm}$ was monitored by a microplate reader.

2.6. siRNA Transfection. Nrf2 knockdown cell model and HO-1 knockdown cell model were established by transfection with specific siRNA as we previously reported [19]. In brief, cells were plated in 6-well plates and transiently transfected with $70 \mathrm{nM}$ of small interfering oligonucleotide (siRNA) against Nrf2 or HO-1 (Santa Cruz Biotechnology, USA) or control nonspecific oligonucleotide (ConsiRNA) using lipidbased transfection system (Lipofectamine 3000, Thermo Fisher Scientific) for $5 \mathrm{~h}$. Thereafter, cells were allowed to recover in fresh media for $24 \mathrm{~h}$ according to the manufacturer's protocol. The efficiency of Nrf2 or HO-1 knockdown was confirmed by the detection of the mRNA and protein level quantified by qPCR and Western blot, respectively.

2.7. Western Blotting Analysis. Cells were lysed with ice-cold RIPA buffer (Applygen Technologies) containing protease and phosphatase inhibitors (Applygen Technologies). Protein samples were collected and resolved by $8 \%$ or $12 \%$ SDS-PAGE and were then transferred to polyvinylidene difluoride membranes (PVDF) (Millipore, USA). Membranes were blocked with 5\% nonfat milk in TBS containing
$0.1 \%$ Tween 20 (TBS-T) for $4 \mathrm{~h}$ and incubated with primary antibodies at $4^{\circ} \mathrm{C}$ overnight, followed by $1 \mathrm{~h}$ incubation with horseradish peroxidase-conjugated secondary antibodies (Santa Cruz Biotechnology) at room temperature. The blots were detected using ECL detection system (Applygen Technologies) and recorded by chemiluminescence imaging analysis. Images were analyzed using ImageJ software (National Institutes of Health, USA).

2.8. Statistical Analysis. All values were expressed as the mean \pm SD from 3 independent experiments. Statistical analyses were performed by one-way ANOVA followed by Dunnett's test. Data were analyzed and presented with PASW Statistics 18.0 software (SPSS Inc., USA). A $P$ value $<0.05$ was considered statistically significant.

\section{Results}

3.1. Characterization of the Cytotoxicity of Flutamide in HepG2 Cells. The cytotoxicity of flutamide in HepG2 cells was evaluated by cell viability and LDH leakage. Cells were exposed to flutamide for $24 \mathrm{~h}$ at various concentrations ranging from 0 to $200 \mu \mathrm{M}$. Compared to cells in the control group, cells treated with flutamide at concentrations higher than $25 \mu \mathrm{M}$ showed significant and concentrationdependent decreases in cell viability with an $\mathrm{LC}_{50}$ (lethal concentration required to cause $50 \%$ reduction in cell viability) of $133 \mu \mathrm{M}$ (Figure 1(a)). The activity of LDH in media was also concentration dependently increased by flutamide. In line with cell viability assay, a significant increase in LDH activity was found in cells treated with flutamide at concentrations higher than $25 \mu \mathrm{M}$ (Figure 1(b)).

3.2. Flutamide-Induced ROS Accumulation and Mitochondrial Dysfunction. Excessive ROS production has been implicated as an important causative factor for flutamide-induced hepatotoxicity [20]. Hydrogen peroxide is one of the main types of ROS that can directly attack 


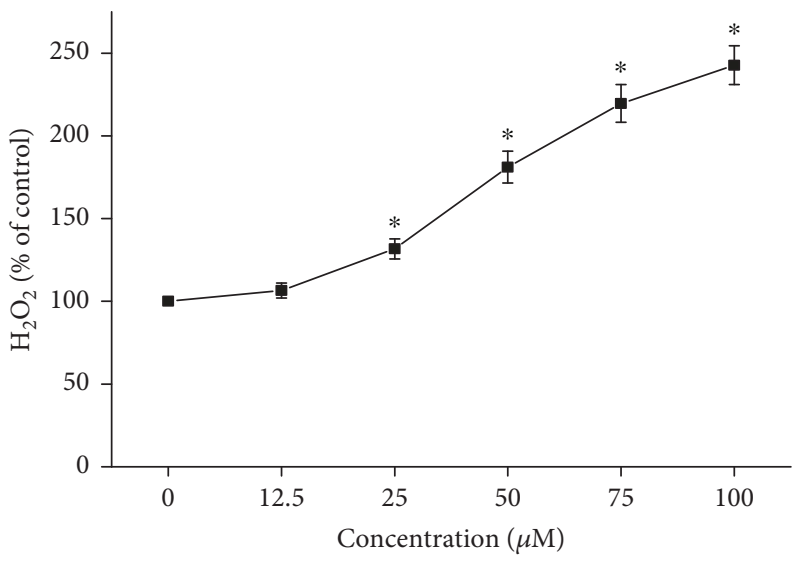

(a)

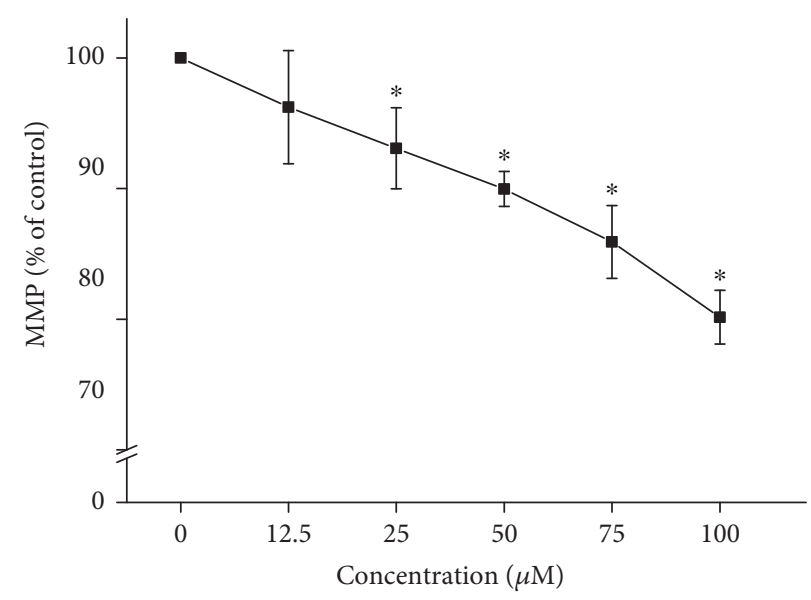

(b)

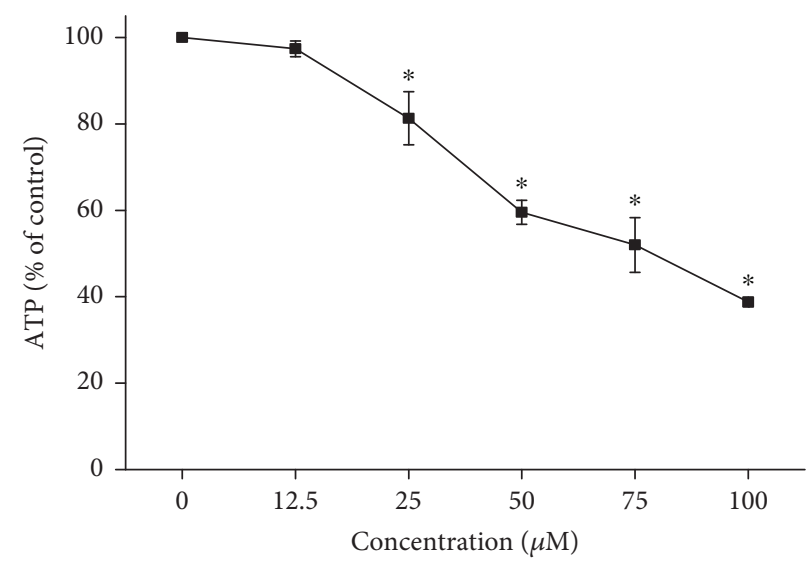

(c)

Figure 2: Flutamide increased hydrogen peroxide $\left(\mathrm{H}_{2} \mathrm{O}_{2}\right)$ accumulation and elicited mitochondrial dysfunction by a concentrationdependent manner. Cells were treated with flutamide at the concentrations up to $100 \mu \mathrm{M}$ for $24 \mathrm{~h}$. Hydrogen peroxide content was analyzed by a commercial kit based on ferrous oxidation of xylenol orange assay (a). Mitochondrial dysfunction was indicated by determination of mitochondrial membrane potential (b) and ATP content. Data are presented as the mean \pm SD from 3 independent experiments. ${ }^{*} P<0.05$ compared with the cells in the control group without drug treatment.

cellular component, such as lipid, protein, and DNA, leading to oxidative damage [21]. As shown in Figure 2(a), flutamide increased hydrogen peroxide levels by a concentrationdependent manner. Compared with cells in the control group, hydrogen peroxide contents were significantly increased in cells treated with flutamide at concentrations higher than $12.5 \mu \mathrm{M}$. For cells treated with flutamide at $100 \mu \mathrm{M}$, the hydrogen peroxide content was increased by 2.4-fold compared with cells in the control group.

Mitochondrial function was evaluated by the determination of mitochondrial membrane potential and ATP production. As shown in Figure 2(b), flutamide was found to concentration dependently decrease mitochondrial membrane potential. Significant mitochondrial membrane potential loss was found in the cells treated with flutamide at a concentration over $12.5 \mu \mathrm{M}$ compared to cells in the control group. Similar results were found in ATP assays. As shown in Figure 2(c), 28.7\%, 40.5\%, 48.0\%, and 51.2\% reductions in ATP levels were found, respectively, for cells treated with flutamide at $25,50,75$, and $100 \mu \mathrm{M}$ compared to cells in the control group.
3.3. Flutamide-Perturbed Nrf2/HO-1 Pathway. To investigate the effect of flutamide on the Nrf2/HO-1 pathway, the protein expressions of Nrf2, HO-1, and superoxide dismutase-2 (SOD2) were analyzed with Western blot (Figure 3(a)). Protein levels of Nrf2 (Figure 3(b)) and HO-1 (Figure 3(c)) were slightly increased by flutamide at $12.5 \mu \mathrm{M}$ but were significantly decreased by higher concentrations of flutamide. Compared to the cells in the control group, the protein levels of Nrf2 were increased by $13.7 \%$ and decreased by $11.0 \%, 28.7 \%, 42.1$, and $44.0 \%$ for cells treated with flutamide at $12.5,25,50,75$, and $100 \mu \mathrm{M}$, respectively. Remarkable changes were also found in HO-1 protein expression, which was increased by $24.3 \%$ but decreased by $9.0 \%, 63.7 \%, 80.6 \%$, and $84.3 \%$, respectively, for cells treated with flutamide at $12.5,25,50,75$, and $100 \mu \mathrm{M}$, respectively (Figure 3(d)). In contrast, the protein expression of SOD2 was inhibited by flutamide at all concentrations tested with decreases ranging from $12.9 \%$ to $33.1 \%$.

3.4. Knockdown of Nrf2/HO-1 Aggravated FlutamideInduced Oxidative Stress, Mitochondrial Dysfunction, and Inhibition of Nrf2/HO-1 Pathway. To evaluate the role of 

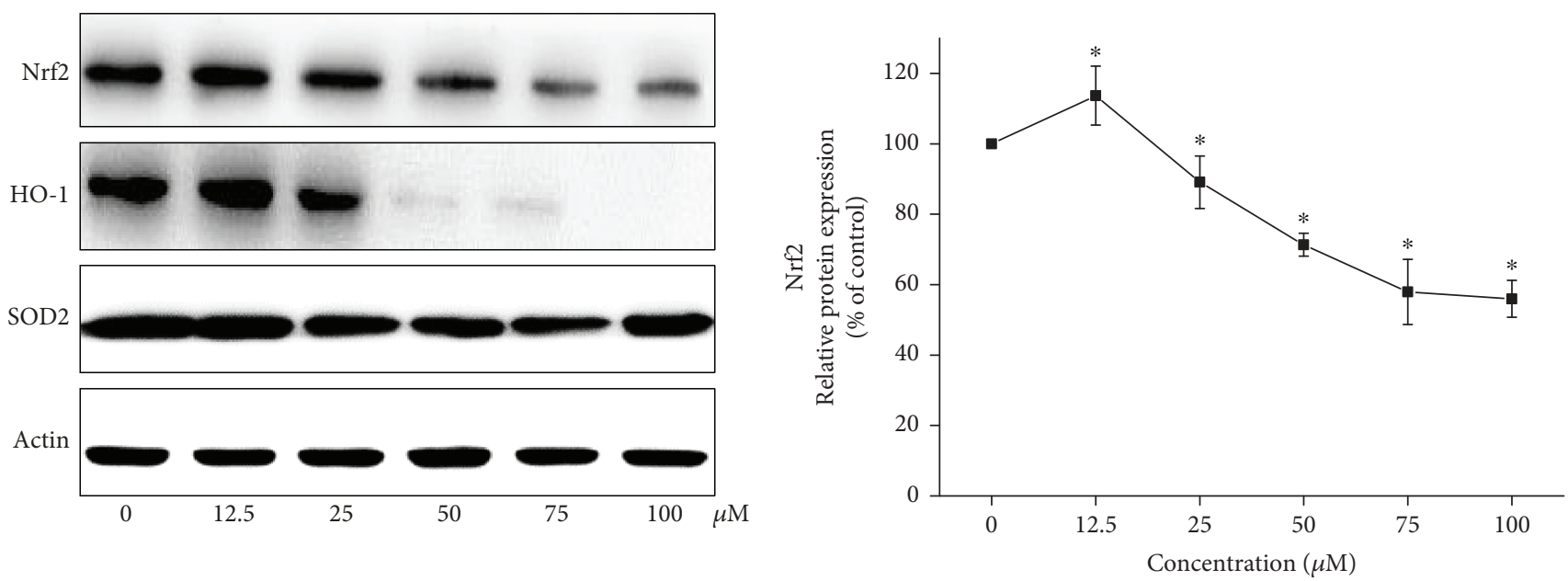

(a)

(b)

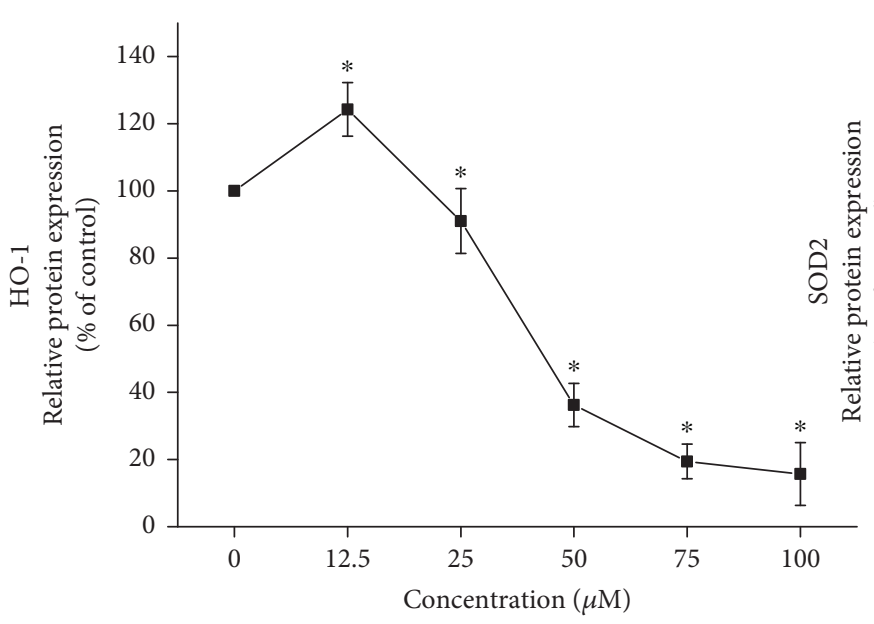

(c)



(d)

FIgURe 3: Effects of flutamide on the Nrf2/HO-1 pathway. Cells were treated with flutamide at the concentrations ranging from $12.5 \mu \mathrm{M}$ to $100 \mu \mathrm{M}$ for $24 \mathrm{~h}$. The protein expressions of Nrf2, HO-1, and SOD2 were measured by Western blot. Representative images of blots are shown in (a). The protein expressions of Nrf2 (b), HO-1 (c), and SOD2 (d) were quantitatively analyzed by ImageJ software. Data are presented as the mean \pm SD from 3 independent experiments. ${ }^{*} P<0.05$ compared with the cells in the control group without drug treatment.

the Nrf2/HO-1 pathway in flutamide-induced hepatotoxicity, Nrf2 knockdown and HO-1 knockdown cell models were established. HepG2 cells were treated with Nrf2 or HO-1 siRNA at a concentration at which no obvious cytotoxicity was elicited. The efficiency of Nrf2 and HO-1 knockdown was confirmed by RT-PCR and Western blot to detect mRNA and protein levels, respectively. The efficiency of Nrf2 and HO-1 knockdown efficiency at protein level were approximately $50 \%$ and $40 \%$ (data not shown).

Nrf2 knockdown by itself showed no tangible effect on the hydrogen peroxide level, mitochondrial membrane potential, and ATP content. However, compared to cells treated with ConsiRNA, $50 \mu \mathrm{M}$ flutamide-induced hydrogen peroxide accumulation, mitochondrial membrane potential loss, and ATP depletion were significantly aggravated in Nrf2 knockdown cells. Flutamide elevated the levels of hydrogen peroxide by 1.7 - and 2.9-fold, respectively, for ConsiRNA-treated cells and Nrf2 knockdown cells (Figure 4(a)). The mitochondrial membrane potential was decreased by $14.5 \%$ and $42.1 \%$, respectively, for ConsiRNAtreated cells and Nrf2 knockdown cells following flutamide exposure (Figure 4(b)). Similarly, flutamide was found to induce $34.5 \%$ and $73.0 \%$ reduction in ATP levels for ConsiRNA-treated cells and Nrf2 knockdown cells, respectively, (Figure 4(c)). As expected, the protein expressions of $\mathrm{Nrf} 2, \mathrm{HO}-1$, and SOD2 were significantly decreased in Nrf2 knockdown cells (Figures 4(d) and 4(e)). Flutamideinduced inhibition of $\mathrm{Nrf} 2$ and $\mathrm{HO}-1$ was further aggravated by Nrf2 knockdown. Interestingly, no significant difference was found in the protein expression of SOD2 between ConsiRNA-treated cells and Nrf2 knockdown cells following flutamide exposure.

Knockdown of HO-1 was also found to exacerbate flutamide-induced oxidative stress and mitochondrial function. The hydrogen peroxide level, mitochondrial membrane potential, and ATP level were not affected by HO-1 silencing (Figures 5(a)-5(c)). HO-1 knockdown only significantly decreased the expression of HO-1 but did not alter the 


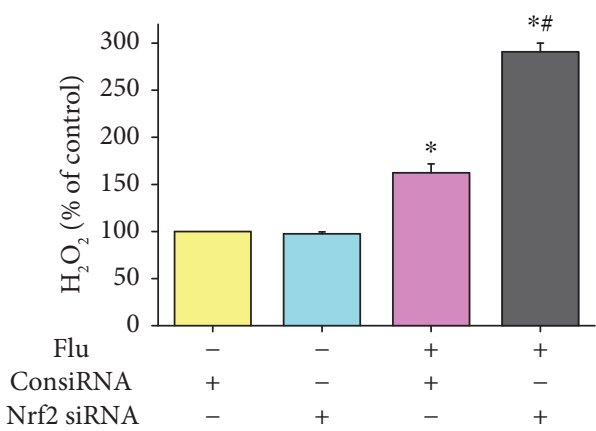

(a)

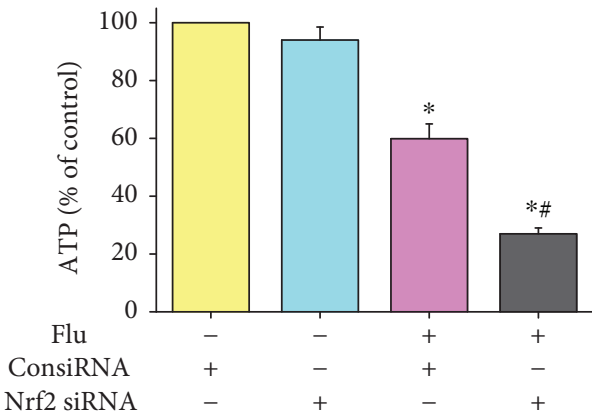

(c)

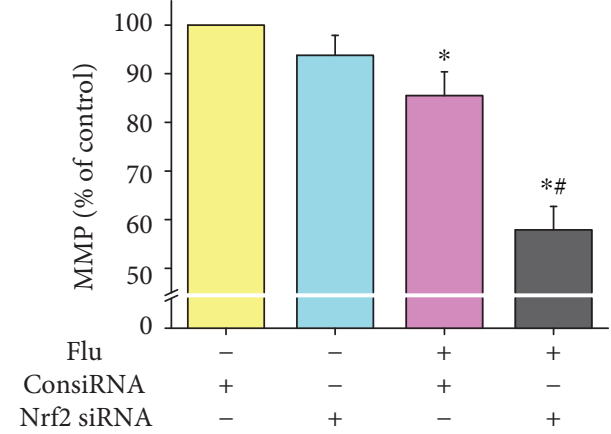

(b)

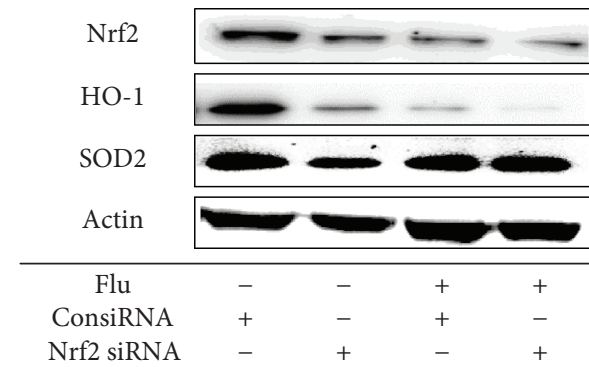

(d)



(e)

Figure 4: Knockdown of Nrf2 aggravated flutamide-induced oxidative stress, mitochondrial dysfunction, and inhibition of the Nrf2/HO1 pathway. ConsiRNA-treated cells and Nrf2-silenced cells were exposed to flutamide at $50 \mu \mathrm{M}$ for $24 \mathrm{~h}$. Afterward, the levels of hydrogen peroxide (a), mitochondrial membrane potential (b), and ATP (c) were determined. The protein expressions of Nrf2, HO-1, and SOD2 were analyzed by Western blot (d) and quantified by ImageJ (e). Data are presented as the mean \pm SD from 3 independent experiments. ${ }^{*} P<0.05$ compared with ConsiRNA-treated cells without drug treatment; ${ }^{\#} P<0.05$ compared with ConsiRNA-treated cells with flutamide treatment.

protein expression of Nrf2 and SOD2 (Figures 5(d) and 5(e)). Compared to cells without drug treatment, the hydrogen peroxide level was increased by 2.1 -fold while the mitochondrial membrane potential and ATP content were decreased by $25.9 \%$ and $54.5 \%$, respectively, in HO-1 knockdown cells treated with $50 \mu \mathrm{M}$. Silencing of HO-1 exacerbated flutamide-induced inhibition of $\mathrm{HO}-1$ protein expression, but no significant difference was found in the protein expression of Nrf2 and SOD2 between ConsiRNA-treated cells and HO-1 knockdown cells following flutamide exposure.
3.5. Effects of HO-1 Interventions on Flutamide-Induced Oxidative Stress and Mitochondrial Dysfunction. Given the prominent alterations of $\mathrm{HO}-1$ following flutamide treatment, we further investigated the effect of HO-1 interventions on flutamide-mediated hepatic injury and Nrf2/HO-1 pathway perturbation. Cells were pretreated with $10 \mu \mathrm{M}$ Copp (HO-1 inducer) or $20 \mu \mathrm{M}$ Snpp (HO-1 inhibitor) for $1 \mathrm{~h}$ before flutamide $(50 \mu \mathrm{M})$ treatment. Copp significantly blocked flutamide-induced oxidative stress and mitochondrial dysfunction, while inhibition of HO-1 by Snpp 


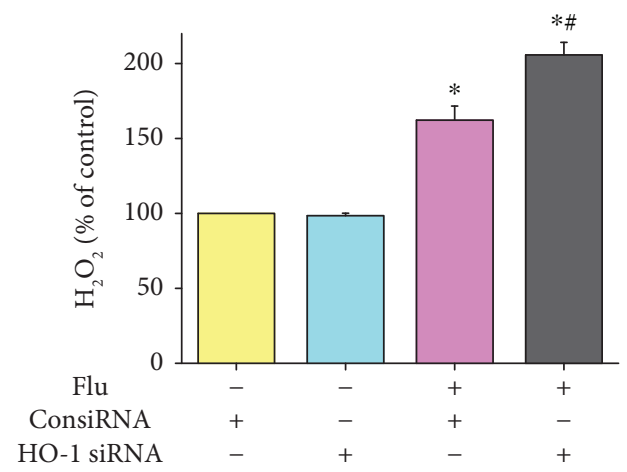

(a)

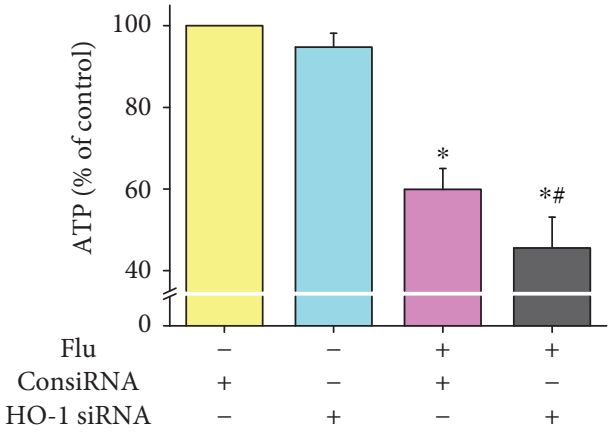

(c)

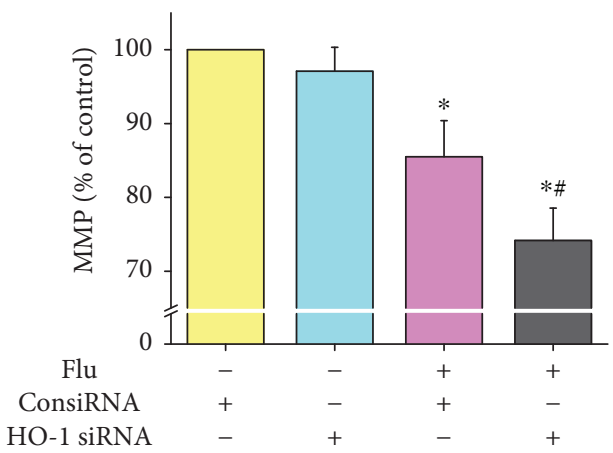

(b)

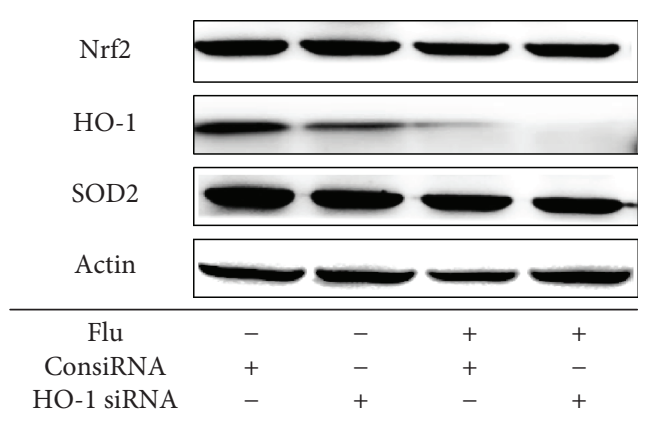

(d)

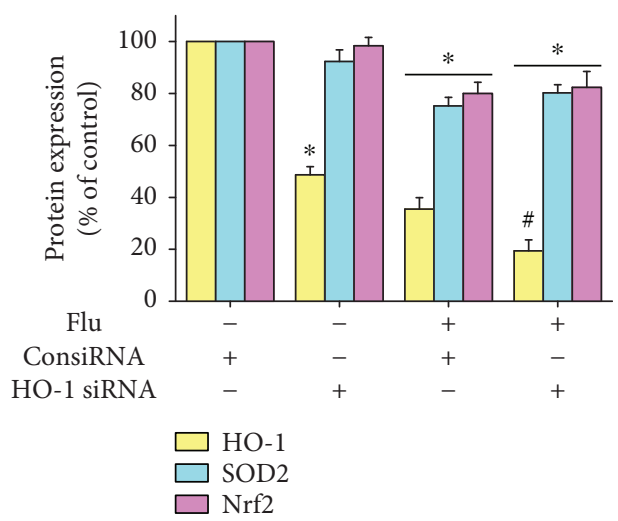

(e)

Figure 5: Knockdown of HO-1 exacerbated flutamide-induced oxidative stress and mitochondrial dysfunction. ConsiRNA-treated cells and Nrf2-silenced cells were exposed to flutamide at $50 \mu \mathrm{M}$ for $24 \mathrm{~h}$. Afterward, the levels of hydrogen peroxide (a), mitochondrial membrane potential (b), and ATP (c) were determined. The protein expressions of Nrf2, HO-1, and SOD2 were analyzed by Western blot (d) and quantified by ImageJ (e). Data are presented as the mean \pm SD from 3 independent experiments. ${ }^{*} P<0.05$ compared with ConsiRNAtreated cells without drug treatment; ${ }^{\#} P<0.05$ compared with ConsiRNA-treated cells with flutamide treatment.

remarkably aggravated these deleterious effects. Compared to cells in the control group without drug treatment, the levels of hydrogen peroxide in cells treated with flutamide, Snpp plus flutamide, and Copp plus flutamide were elevated by 1.9-, 2.1-, and 1.4-fold, respectively (Figures 6(a)-6(c)). The mitochondrial membrane potential and ATP content were reduced by 27.5 and $48.6 \%$ in cells treated with Snpp plus flutamide. In comparison, cells treated with Copp only showed a $7.0 \%$ reduction in mitochondrial membrane potential and $17.8 \%$ decrease in ATP content. Results from Western blot analysis showed that Snpp pretreatment significantly potentiated flutamide-induced inhibition of Nrf2 and HO-1 protein expression (Figures 6(d) and 6(e)), while Copp can ameliorate these changes by flutamide (Figures 6(f) and 6(g)). Neither Snpp nor Copp has an obvious effect on flutamide-induced inhibition of SOD2 expression.

\section{Discussion}

Flutamide is an antiandrogen drug that is widely used for the treatment of prostate cancer. However, the therapeutic effects 


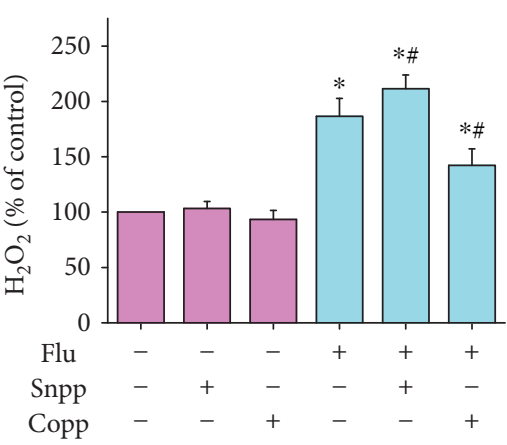

(a)

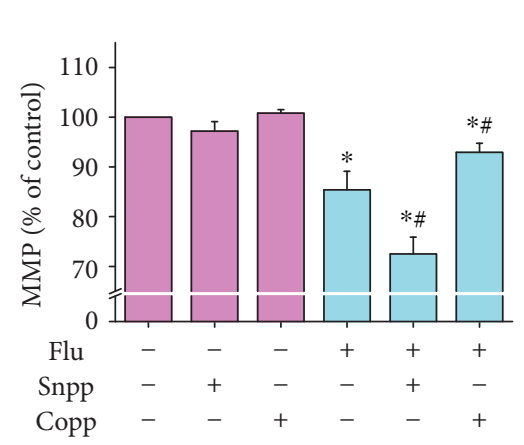

(b)

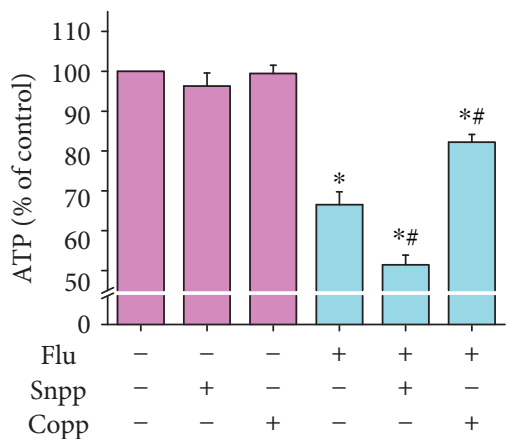

(c)

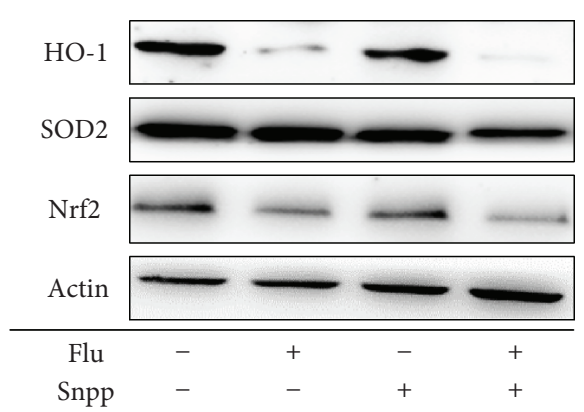

(d)

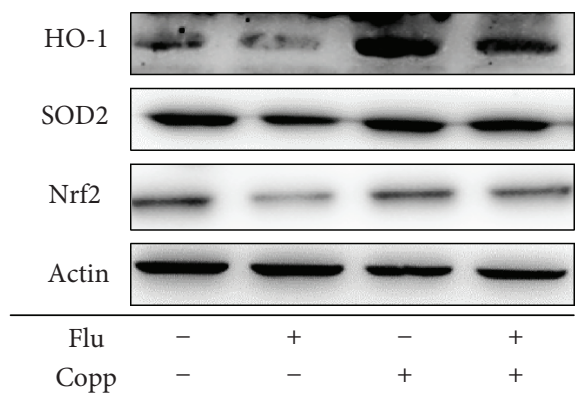

(f)

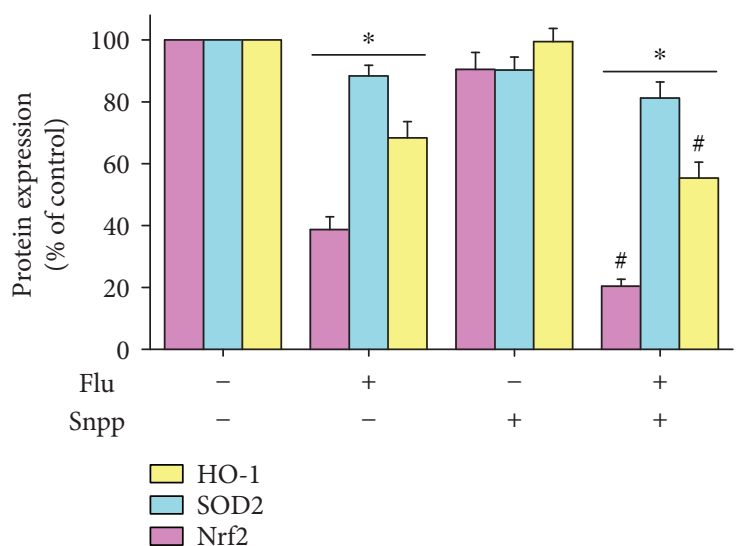

(e)

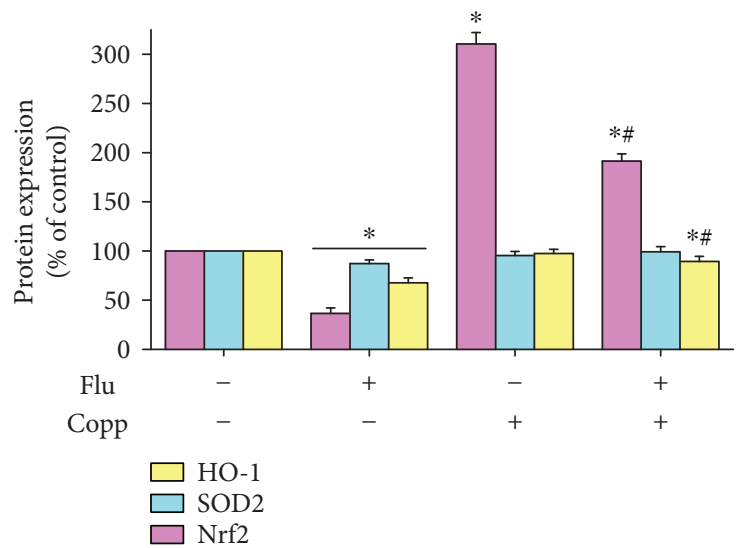

(g)

FIGURE 6: Effects of HO-1 interventions on flutamide-induced oxidative stress and mitochondrial dysfunction. Cells were pretreated with or without $20 \mu \mathrm{M}$ Snpp $/ 10 \mu \mathrm{M}$ Copp for $1 \mathrm{~h}$ followed by treatment with $50 \mu \mathrm{M}$ flutamide. After completion of drug treatments, the levels of hydrogen peroxide (a), mitochondrial membrane potential (b), and ATP (c) as well as the protein expressions of Nrf2, HO-1, and SOD2 were analyzed $(\mathrm{d}-\mathrm{f})$. Data are presented as the mean $\pm \mathrm{SD}$ from 3 independent experiments. ${ }^{*} P<0.05$ compared with the cells in the control group without drug treatment; ${ }^{\#} P<0.05$ compared with the cells treated with flutamide.

of flutamide have been overshadowed by reports of liver dysfunction in $1-10 \%$ of its users $[2,22]$. This flutamide-induced liver injury is not acute but delayed [3,23]. In most cases, flutamide caused liver dysfulnction after a latency period of approximately 16 weeks [24]. Our results demonstrated that $24 \mathrm{~h}$ treatment of HepG2 cells with flutamide concentration dependently induced reduction of cell viability and $\mathrm{LDH}$ leakage. Flutamide did not elicit significant effects on these cytotoxicity indices at the concentration of 12.5 and $25 \mu \mathrm{M}$. Thus, the observed adverse effect level (NOAEL) of flutamide-induced cytotoxicity in HepG2 cells is $25 \mu \mathrm{M}$. Flutamide-induced mitochondrial damage was evaluated by the determination of mitochondrial membrane potential and ATP production. Our results showed that flutamide 


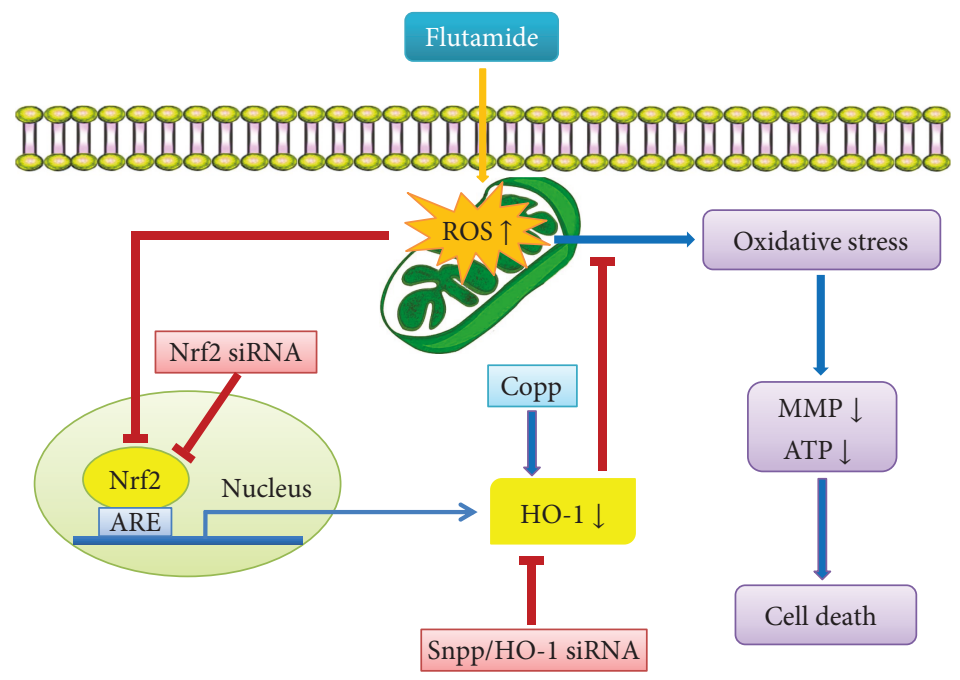

Figure 7: Schematic representation of the role of Nrf2-mediated HO-1 in flutamide-induced hepatic cell death and mitochondrial dysfunction.

concentration dependently decreased mitochondrial membrane potential and reduced the APT level. Significant mitochondrial toxic effects were found at the concentration of $25 \mu \mathrm{M}$ at which no significant cytotoxicity was observed induced, suggesting mitochondria as a sensitive target of flutamide-induced hepatocyte toxicity.

Mitochondria are thought to play a critical role in the development and pathogenesis of drug-induced liver injury, not only due to their role as the main source of endogenous ROS but also due to the role as the target of ROS attack. It has been shown that the accumulation of ROS in hepatic cells is an essential step in flutamide hepatotoxicity [4]. It is implicated that flutamide can promote ROS generation, especially in the mitochondria, by multiple mechanisms [10]. For instance, flutamide has been shown to inhibit mitochondrial complex I leading to superoxide production through the reduction of molecular oxygen by the NADH/ubiquinone oxidoreductase [25]. Flutamide can also produce many reactive oxidants during its metabolism in the liver. In the present study, flutamide was found to increase the level of hydrogen peroxide in a concentration-dependent manner; however, the specific source of the observed flutamide-elicited ROS accumulation still needs further investigation.

Excessive ROS generation can disrupt mitochondrial membrane potential, induce mitochondrial dysfunction, and compromise the capacity of the antioxidant defense system [26]. The mitochondria have been indicated as important targets of flutamide-mediated adverse effects in the liver. It has been shown that flutamide can alter mitochondrial morphology and profoundly downregulate genes associated with fatty acid $\beta$-oxidation and upregulate genes related to antioxidant defense in hepatocytes [6]. The loss of ATP was also found to be a critical event in the cytotoxicity of flutamide caused by its ability to target complex I of the electron transport chain and impair oxidative phosphorylation [6]. Consistent with the observation of increased hydrogen peroxide accumulation, our results demonstrated that flutamide induced mitochondrial membrane potential loss and reduction of ATP.

Nrf2 is ubiquitously expressed throughout human tissues, with high expression in detoxification organs, especially the liver. Nrf2 serves as a major regulator of the cellular antioxidant defense pathway by which hepatic cells combat oxidative stress [27, 28]. During oxidative stress, $\mathrm{Nrf} 2$ activation is initiated to transcriptionally regulate its target genes to detoxify and eliminate potentially harmful exogenous chemicals and their metabolites [29, 30]. Growing evidence has suggested that the activation of the $\mathrm{Nrf} 2$ pathway is a key mechanism underlying the protective effects of many pharmacological agents [31, 32]. In contrast, the inhibition of the Nrf2 pathway has been implicated as a critical cause leading to the adverse effects of several chemicals [33]. Nrf2 knockout mice and Nrf2deficient cells have been found to be more sensitive to oxidative injury [34-36]. In the present study, the protein expression of Nrf2 was slightly increased by flutamide at a lower concentration $(12.5 \mu \mathrm{M})$ but was significantly inhibited by higher concentrations $(\geq 50 \mu \mathrm{M})$. Knockdown of $\mathrm{Nrf} 2$ was found to significantly sensitize the cells to flutamide-induced ROS accumulation and mitochondrial dysfunction. The changes of Nrf2 were mirrored by HO-1 and SOD2, though the magnitude of SOD2 alternation was less than Nrf2 and HO-1. These findings suggest that the Nrf2 pathway was activated by flutamide at a low dose to counteract oxidative stress. However, cells exposed to flutamide at a higher dose might undergo saturated Nrf2 pathway activation, thus failing to combat increased ROS generation, consequently leading to inhibition of this pathway and mitochondrial dysfunction.

HO-1 is implicated as one of the most important downstream antioxidant targets of Nrf2 protecting against oxidative stress damage [37-39]. Increasing evidence suggests that $\mathrm{HO}-1$ is particularly important in regulating mitochondrial function and energy metabolism as well as 
oxidative stress $[40,41]$. HO- 1 represents a prime antioxidant defense mechanism against mitochondrial oxidative stress through several ways [42-44]. The induction of HO-1 leads to increased cellular CO production, which generates a redox signal for the induction of mitochondrial biogenesis [45]. HO-1 has also been implicated in the regulation of mitophagy and mitochondrial quality control cycle [46]. Our results demonstrated that HO-1 was induced by flutamide at a low concentration but was inhibited by high concentrations. Compared to the changes of $\mathrm{Nrf} 2$ and SOD2, the alteration of HO-1 was much more prominent, indicating $\mathrm{HO}-1$ as a sensitive marker of liver injury following flutamide treatment. A recent study by Teppner et al. showed that the gene expression of HO-1 was increased but no obvious cytotoxic effects were induced in in vitro cultured rat hepatocytes treated with flutamide at 50 and $100 \mu \mathrm{M}$, which are similar to the concentrations used in the present study [47]. This discrepancy with our results might involve several causes such as different cell models and experimental parameters. In addition, HO-1 silence significantly augmented flutamide-induced oxidative stress and mitochondrial dysfunction. Preinduction of HO-1 by Copp significantly attenuated flutamide-induced ROS accumulation and mitochondrial dysfunction, while inhibition of HO-1 by Snpp remarkably aggravated the deleterious effects. Taken together, these findings suggested that HO-1 was particularly important in flutamideinduced hepatotoxicity (Figure 7).

In conclusion, our results suggested that flutamideinduced hepatotoxicity involves, at least in part, the inhibition of the Nrf2/HO-1 pathway and highlighted an important role of $\mathrm{HO}-1$ in flutamide-induced hepatic mitochondrial injury. The induction of HO-1 prevented flutamide-induced hepatic mitochondrial dysfunction while inhibition of HO-1 exacerbated the adverse effects. These findings provide new evidence to understand the mechanism of flutamide-induced liver injury. Given that oxidative stress and mitochondrial dysfunction underlie the liver injury induced by various drugs, the results obtained from the present study suggest the Nrf2 pathway, particularly $\mathrm{HO}-1$, as a potential therapeutic target for patients with drug-induced adverse effects in the liver.

\section{Data Availability}

The authors are willing to share the detailed/raw data in private with interested researchers.

\section{Additional Points}

Highlights. Flutamide induces cell death, oxidative stress, and mitochondrial dysfunction. The Nrf2/HO-1 pathway was perturbed by flutamide. Knockdown of Nrf2/HO-1 aggravates flutamide-induced hepatic cell injury. Induction of HO-1 prevents hepatic oxidative stress and mitochondrial dysfunction. Inhibition of HO-1 exacerbates flutamideinduced hepatotoxicity.

\section{Conflicts of Interest}

The authors declare no potential conflict of interests with the data presented in this article.

\section{Acknowledgments}

This work was supported by the National Natural Science Foundation of China (81430090), Beijing Nova Program (Z171100001117103), AMMS Innovative Foundation (2017CXJJ13), and Unilever International Collaborative Project (MA-2015-00410).

\section{References}

[1] P. Kang, D. Dalvie, E. Smith, S. Zhou, and A. Deese, "Identification of a novel glutathione conjugate of flutamide in incubations with human liver microsomes," Drug Metabolism and Disposition, vol. 35, no. 7, pp. 1081-1088, 2007.

[2] A. Osculati and C. Castiglioni, "Fatal liver complications with flutamide," Lancet, vol. 367, no. 9517, pp. 1140-1141, 2006.

[3] Z. Thole, G. Manso, E. Salgueiro, P. Revuelta, and A. Hidalgo, "Hepatotoxicity induced by antiandrogens: a review of the literature," Urologia Internationalis, vol. 73, no. 4, pp. 289-295, 2004.

[4] R. Kashimshetty, V. G. Desai, V. M. Kale et al., "Underlying mitochondrial dysfunction triggers flutamide-induced oxidative liver injury in a mouse model of idiosyncratic drug toxicity," Toxicology and Applied Pharmacology, vol. 238, no. 2, pp. 150-159, 2009.

[5] J. Hynes, L. D. Marroquin, V. I. Ogurtsov et al., "Investigation of drug-induced mitochondrial toxicity using fluorescencebased oxygen-sensitive probes," Toxicological Sciences, vol. 92, no. 1, pp. 186-200, 2006.

[6] K. J. Coe, Y. Jia, H. K. Ho et al., "Comparison of the cytotoxicity of the nitroaromatic drug flutamide to its cyano analogue in the hepatocyte cell line TAMH: evidence for complex I inhibition and mitochondrial dysfunction using toxicogenomic screening," Chemical Research in Toxicology, vol. 20, no. 9, pp. 1277-1290, 2007.

[7] A. Al Maruf and P. O'Brien, "Flutamide-induced cytotoxicity and oxidative stress in an in vitro rat hepatocyte system," Oxidative Medicine and Cellular Longevity, vol. 2014, Article ID 398285, 9 pages, 2014.

[8] L. Choucha Snouber, A. Bunescu, M. Naudot et al., "Metabolomics-on-a-chip of hepatotoxicity induced by anticancer drug flutamide and Its active metabolite hydroxyflutamide using HepG2/C3a microfluidic biochips," Toxicological Sciences, vol. 132, no. 1, pp. 8-20, 2013.

[9] N. Rayamajhi, S.-K. Kim, H. Go et al., "Quercetin induces mitochondrial biogenesis through activation of HO-1 in HepG2 cells," Oxidative Medicine and Cellular Longevity, vol. 2013, Article ID 154279, 10 pages, 2013.

[10] M. Teppner, F. Boss, B. Ernst, and A. Pahler, "Application of lipid peroxidation products as biomarkers for flutamideinduced oxidative stress in vitro," Toxicology Letters, vol. 238, no. 3, pp. 53-59, 2015.

[11] R. N. Jadeja, K. K. Upadhyay, R. V. Devkar, and S. Khurana, "Naturally occurring Nrf2 activators: potential in treatment of liver injury," Oxidative Medicine and Cellular Longevity, vol. 2016, Article ID 3453926, 13 pages, 2016. 
[12] C. Gorrini, I. S. Harris, and T. W. Mak, "Modulation of oxidative stress as an anticancer strategy," Nature Reviews Drug Discovery, vol. 12, no. 12, pp. 931-947, 2013.

[13] K. Shukla, H. Sonowal, A. Saxena, K. V. Ramana, and S. K. Srivastava, "Aldose reductase inhibitor, fidarestat regulates mitochondrial biogenesis via $\mathrm{Nrf2/HO}-1 / \mathrm{AMPK}$ pathway in colon cancer cells," Cancer Letters, vol. 411, pp. 57-63, 2017.

[14] R. Gozzelino, V. Jeney, and M. P. Soares, "Mechanisms of cell protection by heme oxygenase-1," Annual Review of Pharmacology and Toxicology, vol. 50, no. 1, pp. 323-354, 2010.

[15] H. Yan, Z. Huang, Q. Bai et al., "Natural product andrographolide alleviated APAP-induced liver fibrosis by activating Nrf2 antioxidant pathway," Toxicology, vol. 396397, pp. 1-12, 2018.

[16] X. Peng, C. Dai, Q. Liu, J. Li, and J. Qiu, "Curcumin attenuates on carbon tetrachloride-induced acute liver injury in mice via modulation of the Nrf2/HO- 1 and TGF- $\beta 1 /$ Smad3 pathway," Molecules, vol. 23, no. 1, p. 215, 2018.

[17] Y.-H. Lee, S. Kim, S. Lee et al., "Antioxidant effect of barley sprout extract via enhancement of nuclear factor-erythroid 2 related factor 2 activity and glutathione synthesis," Nutrients, vol. 9, no. 11, article 1252, 2017.

[18] A. M. Mahmoud, W. G. Hozayen, and S. M. Ramadan, "Berberine ameliorates methotrexate-induced liver injury by activating Nrf2/HO-1 pathway and $\operatorname{PPAR} \gamma$, and suppressing oxidative stress and apoptosis in rats," Biomedicine \& Pharmacotherapy, vol. 94, pp. 280-291, 2017.

[19] W. Zhou, X. Yuan, L. Zhang et al., "Overexpression of HO-1 assisted PM2.5-induced apoptosis failure and autophagyrelated cell necrosis," Ecotoxicology and Environmental Safety, vol. 145, pp. 605-614, 2017.

[20] E. Navarro, L. Gonzalez-Lafuente, I. Pérez-Liébana et al., "Heme-oxygenase I and PCG- $1 \alpha$ regulate mitochondrial biogenesis via microglial activation of Alpha7 nicotinic acetylcholine receptors using PNU282987," Antioxidants \& Redox Signaling, vol. 27, no. 2, pp. 93-105, 2017.

[21] P. R. Angelova and A. Y. Abramov, "Role of mitochondrial ROS in the brain: from physiology to neurodegeneration," FEBS Letters, vol. 592, no. 5, pp. 692-702, 2018.

[22] Y. Nakagawa, M. Koyama, and M. Matsumoto, "Flutamideinduced hepatic disorder and serum concentrations of flutamide and its metabolites in patients with prostate cancer," Hinyokika Kiyo, vol. 45, no. 12, pp. 821-826, 1999.

[23] G. Manso, Z. Thole, E. Salgueiro, P. Revuelta, and A. Hidalgo, "Spontaneous reporting of hepatotoxicity associated with antiandrogens: data from the Spanish pharmacovigilance system," Pharmacoepidemiology and Drug Safety, vol. 15, no. 4, pp. 253-259, 2006.

[24] M. Ohbuchi, M. Miyata, D. Nagai, M. Shimada, K. Yoshinari, and Y. Yamazoe, "Role of enzymatic $N$-hydroxylation and reduction in flutamide metabolite-induced liver toxicity," Drug Metabolism and Disposition, vol. 37, no. 1, pp. 97-105, 2009.

[25] J. F. Turrens, "Mitochondrial formation of reactive oxygen species," The Journal of Physiology, vol. 552, no. 2, pp. 335-344, 2003.

[26] Y. Wang, S. H. Guo, X. J. Shang et al., "Triptolide induces Sertoli cell apoptosis in mice via ROS/JNK-dependent activation of the mitochondrial pathway and inhibition of Nrf2-mediated antioxidant response," Acta Pharmacologica Sinica, vol. 39, no. 2, pp. 311-327, 2017.
[27] C. Knörr-Wittmann, A. Hengstermann, S. Gebel, J. Alam, and T. Müller, "Characterization of Nrf2 activation and heme oxygenase-1 expression in NIH3T3 cells exposed to aqueous extracts of cigarette smoke," Free Radical Biology \& Medicine, vol. 39, no. 11, pp. 1438-1448, 2005.

[28] A. A. Turanov, D. Su, and V. N. Gladyshev, "Characterization of alternative cytosolic forms and cellular targets of mouse mitochondrial thioredoxin reductase," The Journal of Biological Chemistry, vol. 281, no. 32, pp. 22953-22963, 2006.

[29] Y. J. Lee, H. Y. Jeong, Y. B. Kim et al., "Reactive oxygen species and PI3K/Akt signaling play key roles in the induction of Nrf2-driven heme oxygenase-1 expression in sulforaphanetreated human mesothelioma MSTO-211H cells," Food and Chemical Toxicology, vol. 50, no. 2, pp. 116-123, 2012.

[30] J. Wang, L. Yuan, H. Xiao, C. Xiao, Y. Wang, and X. Liu, "Momordin Ic induces HepG2 cell apoptosis through MAPK and PI3K/Akt-mediated mitochondrial pathways," Apoptosis, vol. 18, no. 6, pp. 751-765, 2013.

[31] E. Y. Lin, U. Bayarsengee, C. C. Wang, Y. H. Chiang, and C. W. Cheng, "The natural compound 2,3,5,4'-tetrahydroxystilbene2 -O- $\beta$-dglucoside protects against adriamycin-induced nephropathy through activating the Nrf2-Keap1 antioxidant pathway," Environmental Toxicology, vol. 33, no. 1, pp. 7282, 2018.

[32] G. R. Sharath Babu, T. Anand, N. Ilaiyaraja, F. Khanum, and N. Gopalan, "Pelargonidin modulates Keap1/Nrf2 pathway gene expression and ameliorates citrinin-induced oxidative stress in HepG2 cells," Frontiers in Pharmacology, vol. 8, p. 868, 2017.

[33] D. Ren, N. F. Villeneuve, T. Jiang et al., "Brusatol enhances the efficacy of chemotherapy by inhibiting the Nrf2-mediated defense mechanism," Proceedings of the National Academy of Sciences of the United States of America, vol. 108, no. 4, pp. 1433-1438, 2011.

[34] Y. Wei, J. Gong, Z. Xu et al., "Nrf2 in ischemic neurons promotes retinal vascular regeneration through regulation of semaphorin 6A," Proceedings of the National Academy of Sciences of the United States of America, vol. 112, no. 50, pp. E6927-E6936, 2015.

[35] U. A. Köhler, S. Kurinna, D. Schwitter et al., "Activated Nrf2 impairs liver regeneration in mice by activation of genes involved in cell-cycle control and apoptosis," Hepatology, vol. 60, no. 2, pp. 670-678, 2014.

[36] A. A. Merchant, A. Singh, W. Matsui, and S. Biswal, "The redox-sensitive transcription factor $\mathrm{Nrf} 2$ regulates murine hematopoietic stem cell survival independently of ROS levels," Blood, vol. 118, no. 25, pp. 6572-6579, 2011.

[37] A. Loboda, A. Jazwa, A. Grochot-Przeczek et al., "Heme oxygenase-1 and the vascular bed: from molecular mechanisms to therapeutic opportunities," Antioxidants \& Redox Signaling, vol. 10, no. 10, pp. 1767-1812, 2008.

[38] A. Jozkowicz, H. Was, and J. Dulak, "Heme oxygenase-1 in tumors: is it a false friend?," Antioxidants \& Redox Signaling, vol. 9, no. 12, pp. 2099-2118, 2007.

[39] Y. J. Jun, M. Lee, T. Shin, N. Yoon, J. H. Kim, and H. R. Kim, "Eckol enhances heme oxygenase-1 expression through activation of Nrf2/JNK pathway in HepG2 cells," Molecules, vol. 19, no. 10, pp. 15638-15652, 2014.

[40] W. Yan, D. Li, T. Chen, G. Tian, P. Zhou, and X. Ju, "Umbilical cord MSCs reverse D-galactose-induced hepatic mitochondrial dysfunction via activation of $\mathrm{Nrf} 2 / \mathrm{HO}-1$ 
pathway," Biological \& Pharmaceutical Bulletin, vol. 40, no. 8, pp. 1174-1182, 2017.

[41] T. Kimura and Y. Watanabe, "Tryptophan protects hepatocytes against reactive oxygen species-dependent cell death via multiple pathways including Nrf2-dependent gene induction," Amino Acids, vol. 48, no. 5, pp. 1263-1274, 2016.

[42] H. Was, J. Dulak, and A. Jozkowicz, "Heme oxygenase-1 in tumor biology and therapy," Current Drug Targets, vol. 11, no. 12, pp. 1551-1570, 2010.

[43] D. Goven, A. Boutten, V. Lecon-Malas, J. Boczkowski, and M. Bonay, "Prolonged cigarette smoke exposure decreases heme oxygenase-1 and alters Nrf2 and Bach1 expression in human macrophages: roles of the MAP kinases ERK(1/2) and JNK," FEBS Letters, vol. 583, no. 21, pp. 3508-3518, 2009.

[44] L. Liang, C. Gao, M. Luo et al., "Dihydroquercetin (DHQ) induced HO-1 and NQO1 expression against oxidative stress through the Nrf2-dependent antioxidant pathway," Journal of Agricultural and Food Chemistry, vol. 61, no. 11, pp. 2755-2761, 2013.

[45] C. A. Piantadosi and H. B. Suliman, "Redox regulation of mitochondrial biogenesis," Free Radical Biology \& Medicine, vol. 53, no. 11, pp. 2043-2053, 2012.

[46] T. D. Hull, R. Boddu, L. Guo et al., "Heme oxygenase-1 regulates mitochondrial quality control in the heart," JCI Insight, vol. 1, no. 2, p. e85817, 2016.

[47] M. Teppner, F. Boess, B. Ernst, and A. Pahler, "Biomarkers of flutamide-bioactivation and oxidative stress in vitro and in vivo," Drug Metabolism and Disposition, vol. 44, no. 4, pp. 560-569, 2016. 


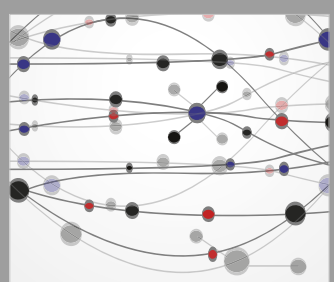

The Scientific World Journal
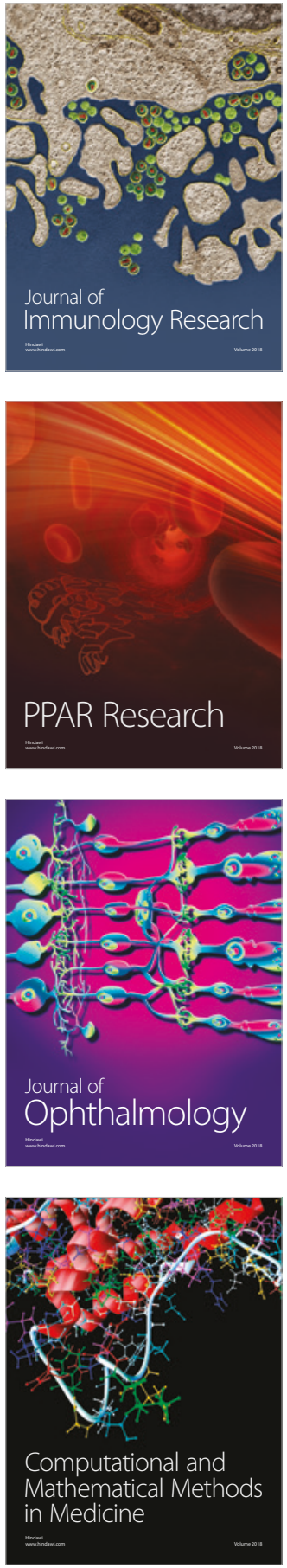

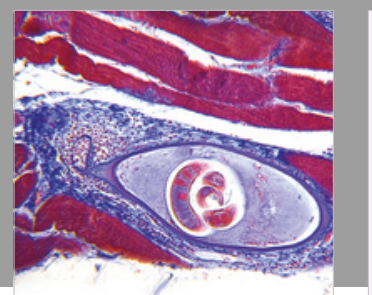

Gastroenterology Research and Practice

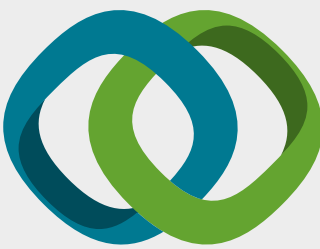

\section{Hindawi}

Submit your manuscripts at

www.hindawi.com
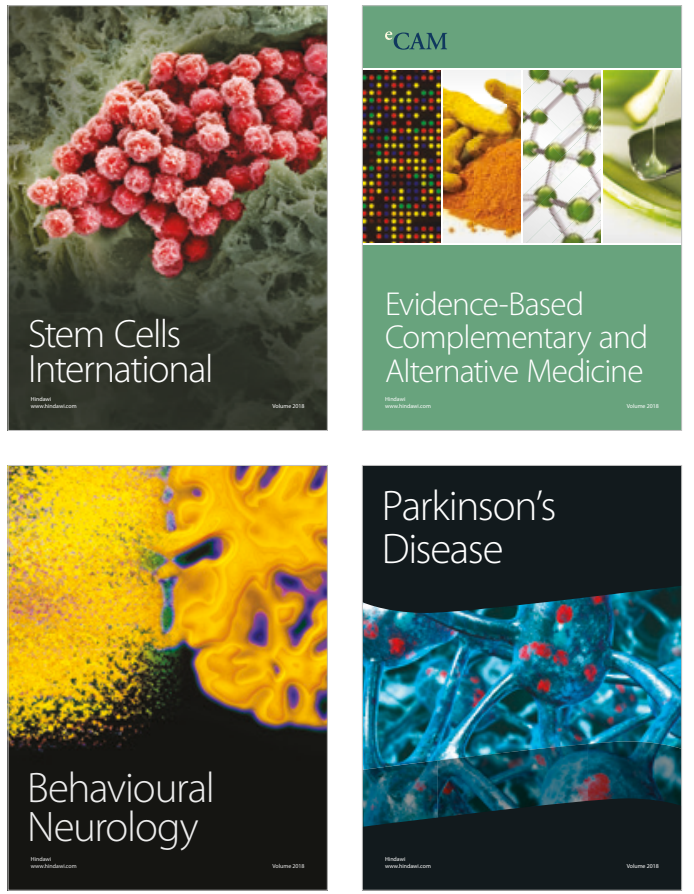

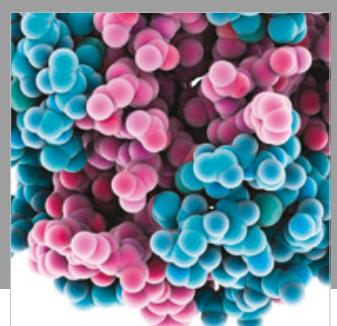

ournal of

Diabetes Research

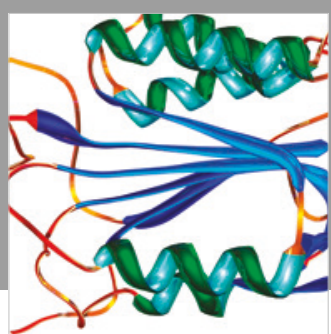

Disease Markers
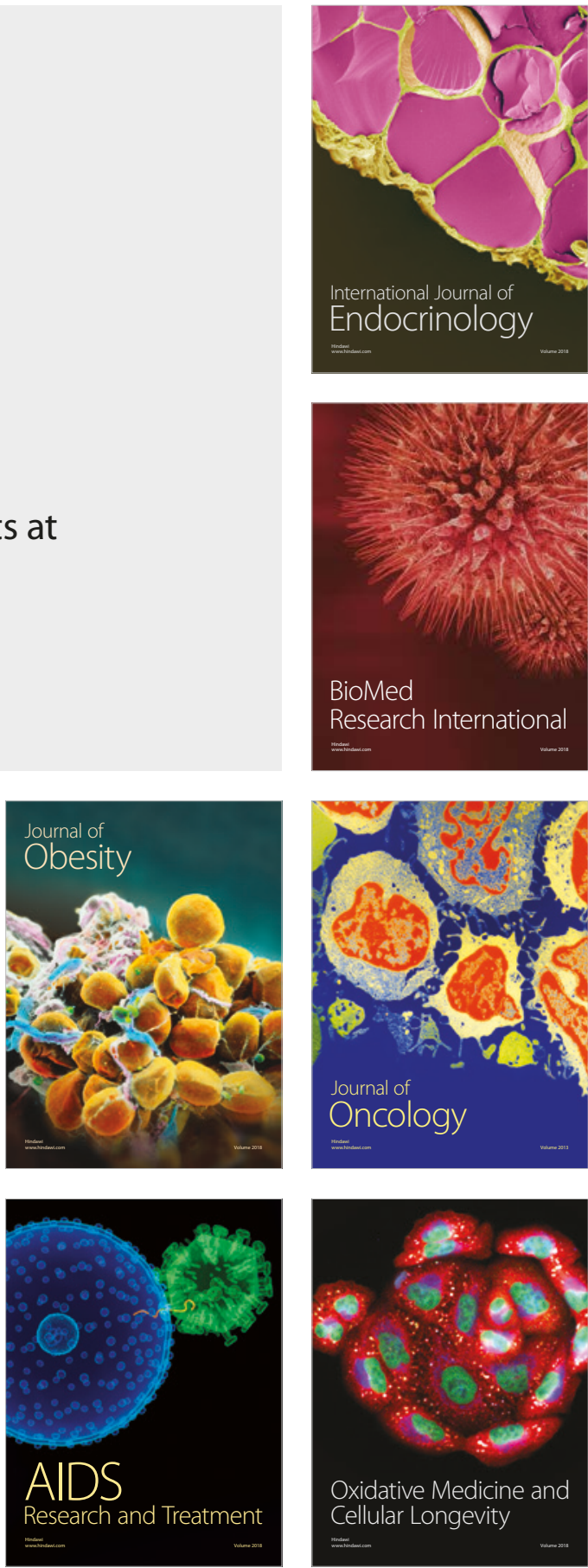